\title{
Limites sociológicos da leitura foucaultiana sobre a escolarização
}

\section{Sociological limits of Foucauldian reading on schooling}

\author{
Norberto Dallabrida ${ }^{1}$
}

\begin{abstract}
RESUMO
Na obra Vigiar e Punir, Michel Foucault reflete sobre o poder disciplinar, que emergiu no início da Idade Moderna em diferentes instituições sociais e consolidou-se no século XIX, tendo como principais estratégias a organização do espaço, o controle do tempo, a vigilância panóptica, a organização das forças e a produção contínua de registros escritos. Nessa obra, são citados vários exemplos de instituições escolares que colocaram em marcha o poder disciplinar, como os colégios jesuíticos, as escolas elementares de caridade dos lassalistas e o ensino mútuo. O presente artigo procura colocar o foco sobre esses casos de escolarização lidos por Foucault, procurando problematizá-los à luz de trabalhos sociológicos inspirados em Norberto Elias e Pierre Bourdieu, que usam marcadores sociais como gênero e classe social para compreender a sociedade e a escola.
\end{abstract}

Palavras-chave: Michel Foucault; escolarização; disciplina; classe social.

\begin{abstract}
In the work Discipline and Punish, Michel Foucault thinks over the discipline power, that emerged at the early modern age in different social institutions, and consolidated in the $19^{\text {th }}$ century, having as main strategies the organization of the space, the time control, the panoptic surveillance, the organization of forces and the continuous production of written records. In this work several examples of school institutions that set in motion the discipline power are quoted, such as Jesuit schools, elementary schools of charity from Lasallian, and the mutual education. This article aims to put the focus over this schooling cases read by Foucault aiming to problematize
\end{abstract}

1 Universidade do Estado de Santa Catarina. Florianópolis, Santa Catarina, Brasil. R. Madre Benvenuta, $n^{\circ} 2007$ - Itacorubi. CEP: 88035-001. 
them aware of sociological works inspired by Norberto Elias and Pierre Bourdieu, that use social markers as gender and social class to understand society and school.

Keywords: Michel Foucault; schooling; discipline; social class.

Uma das questões que ocupou o filósofo-historiador Michel Foucault foi a compreensão em perspectiva temporal de longa duração - ou genealógica, como ele preferia chamá-la - das modalidades de poder. Em Vigiar e punir (FOUCAULT, 1993) - obra de meados dos anos 1970, que teve grande repercussão no meio acadêmico - colocou-se o foco sobre o poder disciplinar ou disciplina, procurando diferenciá-lo de outras formas de poder. O subtítulo desse livro é "nascimento da prisão", mas, em realidade, Foucault procura perceber o nascimento da disciplina na França - e no Ocidente. Segundo Machado (1979), os traços do poder disciplinar são a organização do espaço, que esquadrinha e individualiza os corpos; o controle do tempo, sujeitando os corpos a um ritmo cronológico com o intuito de fazê-lo mais eficaz; a vigilância permanente materializada por meio de uma multiplicidade de olhares; a organização das forças, que constitui corpos institucionais eficazes; e a produção de "um registro contínuo do conhecimento", ou seja, o controle é também e principalmente realizado por anotações escritas que formam um arquivo. No exercício do poder, essas dimensões estão inter-relacionadas e se alimentam mutuamente, azeitando a maquinaria disciplinar.

Foucault sublinha que o poder disciplinar é específico e suas estratégias de ação têm singularidade histórica, que o diferencia da escravidão, que se apropria dos corpos, da vassalidade, "uma relação de submissão altamente codificada", e do ascetismo monástico, baseado em renúncias e em obediência a um religioso hierarquicamente superior. Essa forma disciplinar de exercício do poder por meio de diversos mecanismos de regulação corporal brotou historicamente em várias instituições sociais, formando uma rede que se alimenta e se reforça. Assim, para Foucault o poder não emana de forma centralizada e única do Estado, mas é uma relação que se exerce e se espraia em diferentes espaços sociais, sendo sempre contraposto por táticas de resistências. Além de ser capilar, o poder disciplinar procura sobremaneira produzir, construir, persuadir, incitar porque tem o intuito de plasmar sujeitos dóceis e produtivos. Foucault (1993, p. 127) esclarece:

O momento histórico das disciplinas é o momento em que nasce uma arte do corpo humano, que visa não unicamente o aumento de suas 
habilidades, nem tampouco aprofundar sua sujeição, mas a formação de uma relação que no mesmo mecanismo o torna tanto mais obediente quanto é mais útil, e inversamente.

A questão central em Vigiar e punir é a expansão do poder disciplinar na chamada "época clássica" e a sua consolidação no século XIX. Foucault constata práticas disciplinares esparsas nos conventos medievais, que tinham uma função negativa e, por isso, chama-as de "disciplinas-bloco". Embora tenha tido esses começos parciais e pontuais no Medievo, Foucault afirma que, na "época clássica", houve "inversão funcional" e disseminação da disciplina. Nesse momento histórico, as práticas disciplinares ganharam uma função positiva em que o corpo dos seres humanos passou a ser incitado, enquadrado em tempos cronológicos, esquadrinhado em espaços produtivos e vigiado de forma permanente, configurando a "disciplina-mecanismo". Assim, os começos parciais e a posterior disseminação da disciplina podem ser comparados a vários afluentes que deságuam num grande rio.

Sobre a "época clássica" focalizada em Vigiar e punir, Ó (2005, p. 16) afirma que "Foucault mostra como os problemas do governo explodiram e se passaram a espraiar em várias direções”. A partir do século XVI, o poder disciplinar foi inventado e reinventado, de forma significativa, em diversas instituições sociais como nas manufaturas, nas igrejas protestantes e católico-tridentinas, nos quartéis, nas escolas e colégios, que formaram, de modo lento e ardiloso, uma rede de instituições disciplinares. No tumultuado início da Idade Moderna, também emergiram tratados que tematizavam a "arte de governar" os súditos dos Estados absolutistas, os fiéis das igrejas reformadas, os alunos, as crianças no seio das famílias, etc. Nessa direção, Foucault (1993, p.184-185) anota de forma clara, ao dizer:

Realizou-se uma generalização disciplinar, atestada pela física benthamiana do poder, no decorrer da era clássica. Comprova-o a multiplicação de instituições de disciplina, com sua rede que começa a cobrir uma superfície cada vez mais vasta, e principalmente a ocupar um lugar cada vez menos marginal; o que era ilha, local privilegiado, medida circunstancial ou modelo singular, torna-se fórmula geral; as regulamentações características dos exércitos protestantes e piedosos de Guilherme de Orange ou de Gustavo Adolfo se transformaram em regulamentos para todos os exércitos da Europa; os colégios modelos dos jesuítas, ou escolas de Batencour e de Demia, depois da de Sturm, 
esboçam as formas gerais da disciplina escolar; a ordem estabelecida nos hospitais marítimos e militares serve de esquema para toda a reorganização hospitalar do século XVIII [grifos nossos].

Como processo de temporalidade longa e desdobrada, o poder disciplinar consolidou-se, na França e no espaço europeu, no século XIX, formatando a sociedade panóptica, cujo modelo focalizado em Vigiar e punir é a prisão ortopédica. Trata-se de um momento histórico em que as instituições disciplinares já existentes como escolas, quartéis, associações religiosas e filantrópicas são reinventadas e aprimoradas e novos e específicos espaços institucionais de controle, como o hospício e a prisão, são criados. Esse investimento refinado na produção de sujeitos dóceis e produtivos estava umbilicalmente ligado à afirmação do capitalismo industrial no espaço europeu, pois, segundo Machado (1979, p. XV), "o que as análises de Foucault querem mostrar é que a dominação capitalista não conseguiria se manter se fosse exclusivamente baseada na repressão". Ou seja, o processo de acumulação de capital e de seres humanos é interdependente e simbiótico.

Michel Foucault não se ocupou especificamente da história genealógica das instituições educativas, mas, em suas obras, analisa fragmentos de modelos de escolarização. Em Vigiar e punir ele cita vários exemplos de instituições escolares na "época clássica" que colocaram em marcha o poder disciplinar, como os colégios jesuíticos, as escolas paroquiais, as escolas elementares de caridade dos Irmãos das Escolas Cristãs e o método mútuo. O presente trabalho procura colocar o foco sobre esses casos de escolarização moderna lidos por Foucault, procurando ressaltar a argúcia de sua seleção e problematizá-los à luz de trabalhos sociológicos, especialmente aqueles inspirados na obra de Norberto Elias e na perspectiva bourdieusiana. Esse viés de análise coloca em relevo os conceitos de frações de classes social, pensadas a partir da conjugação de recursos econômicos, de redes de relações sociais e de acumulação de capital cultural e escolar.

Ademais, para compreender a leitura foucaultiana de casos de escolarização na Idade Moderna, usa-se o conceito de currículo escolar, concebido como um artefato cultural e histórico inventado e reinventado ao longo da história, a partir de tensões e concessões provisórias entre proposições cognitivas entranhadas de relações de poder (GOODSON, 1995; POPKEWITZ, 1994). Nessa direção, o currículo prescreve saberes e condutas a serem ensinados, que são selecionados e didatizados a partir dos conhecimentos científicos e artísticos e, de outra parte, coloca-os em prática por meio de dispositivos de transmissão e de avaliação. O currículo, portanto, transmite saberes e inculca comportamentos. 


\section{Disciplina e escolarização}

Ao tentar compreender os dispositivos disciplinares que nasceram em diferentes espaços sociais, Foucault cita vários exemplos de instituições escolares que passaram por relevante deslocamento em relação às práticas educativas medievais. Analisando "a arte das distribuições", que concorre para a docilização dos corpos, Foucault constata que "a disciplina procede em primeiro lugar à distribuição dos indivíduos no espaço". Apoiando-se em Ariès (1981), argumenta que na "época clássica" o internato se afirma como regime de educação mais perfeito e cita como exemplo o Colégio Louis-le-Grand, de Paris, que foi dirigido pelos padres jesuítas desde meados do século XVI e, a partir de 1805, tornou-se o liceu-modelo da Fran$c^{2} a^{2}$. Na conjunção das reformas religiosas e das guerras de religião, a Companhia de Jesus emergiu como a principal congregação católica moderna que instituiu uma rede de colégios internos, que disseminou o modelo conventual, marcado pelo espaço fechado, rompendo com as práticas educativas medievais em que os alunos viviam nas cidades de forma mais solta. O colégio interno, com seus muros que demarcavam fronteiras em relação ao mundo social e sua arquitetura panóptica, era um importante dispositivo disciplinar das instituições escolares pós-medievais.

Foucault refere-se também aos colégios jesuíticos - que pontuaram a França e a Europa católica na Idade Moderna - quando analisa a organização de suas salas de aula. Constata que as turmas eram grandes, constituídas de duzentos ou trezentos alunos, que eram agrupados em decúrias - grupo de dez - divididas entre romanos e cartagineses, que se mantinham em disputa entre si. Cada decúria tinha hierarquia, cujo chefe era o decurião, que proporcionava incitamento permanente dos seus colegas - um dos dispositivos disciplinares mais eficazes da pedagogia moderna. Sobre essa disputa intensa entre os alunos, Foucault (1993, p.133-134) assevera:

A forma geral era a da guerra e da rivalidade; o trabalho, o aprendizado, a classificação eram feitos sob a forma de justa, pela defrontação dos dois exércitos; a participação de cada aluno entrava nesse duelo geral; ele assegurava, por seu lado, a vitória ou as derrotas de um campo; e os alunos determinavam um lugar que correspondia à função de cada um e a seu valor de combatente no grupo unitário de sua decúria.

2 Segundo Deheuvels (2006), o atual Lycée Louis-Le-Grand foi durante a maior parte da Idade Moderna um colégio da Companhia de Jesus e passou a ser o liceu de referência na França a partir da reforma Napoleônica do ensino secundário, oficializada em 1802, que criou os liceus públicos. 
O trabalho escolar sistemático e progressivo era estimulado pelos professores jesuítas que, dessa forma, construíram nos seus colégios um modo escolar refinado de disciplina moderna, sendo inscrito e homogeneizado na Ratio Studiorum, que era o conjunto de regras da Companhia de Jesus oficializado no final do século XVI.

Em Vigiar e punir vários dispositivos disciplinares modernos são flagrados no cotidiano das escolas elementares, que ensinavam a ler-escrever-contar. Ao constatar a presença da "vigilância hierárquica" nas instituições disciplinares, Foucault diz que nas escolas paroquiais seiscentistas foram criados cargos de "oficiais", que eram ocupados pelos melhores alunos. Grosso modo, esses auxiliares da disciplina dividiam-se entre os que realizavam tarefas materiais - distribuir tinta e papel, dar sobras aos pobres, entre outras - e aqueles que executavam serviços de fiscalização, como os observadores, os monitores, os visitadores e os intendentes (FOUCAULT, 1993, p.157-158). As escolas paroquiais, estrutura administrativa da Igreja Católica reformada pelo Concílio de Trento, era dirigida pelo pároco ou vigário, que tinha autoridade eclesial e educativa e estava subordinado hierarquicamente a uma diocese - dirigida por um bispo.

Todavia, a maioria dos casos de escolas de ler-escrever-contar são pinçados por Foucault das escolas elementares de caridade dos Irmãos das Escolas Cristãs - os lassalistas. Ao buscar compreender a docilização dos corpos, constata que esse processo é fabricado por meio da importância dada à "racionalização utilitária do detalhe na contabilidade moral e no controle político". Afirma que Jean-Baptiste de La Salle, no seu Tratado sobre as Obrigações dos Irmãos das Escolas Cristãs, faz um elogio às "pequenas coisas", pois acreditava que os grandes santos são esculpidos por pequenos gestos virtuosos praticados com regularidade e persistência. $\mathrm{O}$ fundador dos lassalistas assevera:

Como é perigoso negligenciar as pequenas coisas. É um pensamento bem consolador para uma alma como a minha, pouco indicada para as grandes ações, pensar que a fidelidade às pequenas coisas pode, por um progresso insensível, elevar-nos à mais eminente santidade: porque as pequenas coisas nos dispõem às grandes [...] (FOUCAULT, 1993, p. 129).

A pedagogia lassalista também é citada ao serem abordados os castigos nas instituições disciplinares, que têm a função de reduzir os desvios, procurando construir a normalização. As punições deixam de ser atos espetacularizados e marcados no corpo como os açoites, palmatórias, suplícios, e passam a ser 
exercícios regulares, repetitivos, multiplicados. Foucault (1993, p. 161) cita o fragmento da obra Conduta das Escolas Cristãs, de La Salle, que afirma: "O castigo escrito é, de todas as penitências, a mais honesta para um mestre, a mais vantajosa e a que mais agrada aos pais; [permite] tirar dos próprios erros das crianças maneiras de avançar seus progressos corrigindo-lhes os defeitos; [...]". Foucault também considera que "a punição, na disciplina, não passa de um elemento de um sistema duplo: gratificação-sanção" e refere-se novamente ao fundador dos lassalistas, que criou a maior rede de escolas elementares na França entre o final do século XVII e início da centúria seguinte. La Salle instituiu nas suas escolas um sistema de pontuação, que permitia ao aluno infrator ser perdoado por determinada falta se tivesse "pontos de privilégio", conseguidos por boa conduta. Ademais, ele percebe que nas escolas lassalistas foi introduzido o "espaço serial", em que os alunos eram divididos em classes e ocupados de forma simultânea e permanente, contribuindo para a sua produção e regulação (FOUCAULT, 1993, p. 134) ${ }^{3}$. A partir do final do século XVII, portanto, as escolas lassalistas também colocaram em marcha mecanismos detalhados de disciplina tais como a emulação, a subdivisão em classes, a classificação, a premiação e a punição moral dos alunos.

Outro exemplo explorado em Vigiar e punir é o ensino mútuo. Esse sistema escolar foi criado na Inglaterra, no final do século XVIII, pelo anglicano André Bell e pelo quaker Joseph Lancaster, com o intuito de alfabetizar em massa, e disseminou-se pelo mundo ocidental na primeira metade do século XIX. No seu país de origem, o método chamou-se monitorial, devido à importância dos monitores no processo de aprendizagem, ou lancasteriano, numa referência a um de seus idealizadores, mas na França ficou conhecido com o nome de "mútuo" (LESAGE, 1999, p. 10). Foucault (1993, p. 149) utiliza essa nomenclatura quando afirma:

Do século XVII até a introdução, no começo do século XIX, do método Lancaster, o mecanismo complexo da escola mútua se constituirá numa engrenagem depois da outra: confiaram-se primeiro aos alunos mais velhos tarefas de simples fiscalização, depois de controle de trabalho, em seguida, de ensino; e então no fim das contas, todo o tempo de todos os alunos estava ocupado seja ensinando seja aprendendo. A escola torna-se um aparelho de aprender onde cada aluno, cada nível e cada momento, se estão combinados como deve ser, são permanentemente utilizados no processo geral de ensino.

3 Sobre a pedagogia lassalista, consultar Fiévet (2001), especialmente a terceira parte. 
A escola de ler-escrever-contar, por meio do método mútuo, é destacada para exemplificar "a composição das forças" própria das instituições disciplinares, que põem em funcionamento conjuntos de corpos humanos em ritmo "maquínico" (DUSSEL; CARUSO, 2003, p. 117-133). Sobre "a articulação das forças" como estratégia do poder disciplinar, Foucault (1993, p. 147) esclarece que "a disciplina não é mais simplesmente uma arte de repartir os corpos, de extrair e acumular o tempo deles, mas de compor forças para obter um aparelho eficiente". O ritmo fabril articulado implementado pelo método mútuo já não tinha o intuito de inculcar regras de civilidade cristã como nas pedagogias jesuíticas ou lassaliana, mas concorria para entranhar nos corpos dos alunos o utilitarismo próprio da primeira industrialização (NARODOWSKI, 2008, p. 137-139).

Para a engrenagem disciplinar funcionar com eficácia nas instituições escolares, ela precisa de um "sistema preciso de comando", com sinais claros toques de sino, sineta, palmas, gestos, um olhar do professor ou do responsável da disciplina - que comunicassem a mudança precisa de atividade. Foucault detecta que nas instituições educativas dos Irmãos das Escolas Cristãs havia um "código de sinais" bem definido, mas afirma que no método mútuo a regulação do comportamento é ainda mais intensificada e aperfeiçoada. Ele cita o estudo L'enseignement mutuel en France, que calculou que um aluno estava sujeito a 200 ordens por dia, sem computar as ordens excepcionais, e estava sujeito “[...] só de manhã [a] 26 ordens por voz, 23 por sinais, 37 batidas de campainha e 24 por apito, o que faz um toque de campainha ou de apito cada 3 minutos" (FOUCAULT, 1993, p. 202).

A vigilância panóptica colocava-se de forma ainda mais eficiente do que nos colégios confessionais da Idade Moderna pelo fato de os monitores terem, além do trabalho de transmitir saberes, a função de controlar os diferentes movimentos dos alunos no salão retangular onde se realizavam as aulas. Nesta direção, é importante anotar que Jeremy Bentham, autor de $O$ Panóptico, relido por Foucault em Vigiar e punir para compreender o nascimento da prisão ortopédica, foi um entusiasta do método monitorial (LÓPES; NARODOWSKI, 1999, p. 52). A maquinaria escolar do ensino mútuo incitava de forma permanente ao trabalho regular e reduzia muito a possibilidade de tempo livre e de resistências, evidenciando o traço de "instituição total".

Ademais, em Vigiar e punir Foucault refere-se à "regulamentação" como uma grande estratégia de poder colocada em marcha no final da "época clássica", ou seja, no século XVIII, que obrigava à homogeneização, mas também à individualização, pois permitia determinar os desvios-padrão. Essa regularização foi estabelecida na sociedade em relação aos produtos industriais, à saúde e à educação escolar, processo que mais tarde Foucault chamaria de "governamen- 
talidade" (FOUCAULT, 1979). Sobre a escolarização, Foucault (1993, p. 164), afirma que "o normal se estabelece como princípio de coerção do ensino, com a instauração de uma educação estandardizada e a criação das escolas normais". Pelo fato de Foucault não dar foco ao Estado em Vigiar e punir - embora ele nunca o desconsidera como uma instância de poder -, não dá a devida visibilidade clara à emergência do chamado "estado-educador", que desde a segunda metade do século XVIII procura controlar conteúdos e métodos escolares, bem como a formação de professores em instituições estatais - as escolas normais (PETITAT, $1994 \mathrm{p}$. 141-149). De outra parte, Vigiar e punir tem um recorte temporal que se estende até meados do século XIX, de modo que Foucault não percebeu a efetiva e impactante normalização nacionalizada do ensino primário implementada na França durante a Terceira República, sob a liderança de Jules Ferry (LELIÈVRE, 1999).

Os exemplos de escolarização usados por Foucault em Vigiar e punir para evidenciar a disseminação da disciplina em diversas instituições sociais revelam sensibilidade histórica do filósofo-historiador em relação ao deslocamento que ocorreu nas práticas educativas durante a Idade Moderna. Os colégios jesuíticos, as escolas paroquiais, as escolas elementares de caridade dos lassalistas e o ensino mútuo fazem parte da escolarização moderna que emergiu no mundo pós-medieval, plasmada pela tecnologia disciplinar e tiveram presença marcante no território francês. No entanto, é importante marcar diferenças entre os colégios católicos que integraram o movimento contrarreformista do método lancasteriano, de corte protestante, que surgiu na Inglaterra na época da Revolução Industrial, que refinou os mecanismos disciplinares, foi apropriado pelos nascentes sistemas nacionais de ensino e teve uma disseminação global sem precedentes.

\section{Os limites sociológicos de Foucault}

Ao citar instituições escolares para compreender a invenção e o desdobramento do poder disciplinar entre os séculos XVI e XIX, Foucault não contempla os marcadores sociais como classe social, gênero e religião. Quando aborda a disseminação da disciplina faz referência aos colégios jesuíticos, às escolas elementares de caridade dos lassalistas e ao método mútuo sem se preocupar com os grupos sociais que os frequentavam. Estudos de sociologia histórica como o de Varela e Alvarez-Uría (1991) - que se fundamenta em proposições foucaultianas, mas também apropria-se de reflexões sociológicas de Norbert Elias e Pierre Bourdieu - sugerem que, além das diferenças na seleção e organização dos conteúdos culturais, as instituições escolares têm diferenças signi- 
ficativas em relação ao disciplinamento dos corpos dos alunos e à inculcação de comportamentos. Os sociólogos espanhóis constatam que nos séculos XVI e XVII havia diferentes modos de educação corporal nos diversos estamentos da sociedade espanhola - e em boa medida europeia -, ao afirmarem:

La recogida y educación de los niños pobres en instituciones a las que son destinados poco tiene que ver no sólo con la educación del Príncipe niño sino también con la de los colegiales que además de dedicarse al estudio de materias literarias (gramática, retórica, dialéctica) vedadas para los pobres y al de distintas lenguas entre las que predomina el latín, se entretienen con juegos y espectáculos cultos y adquieren cortesanas maneras mediante la danza, la esgrima, la equitación y otros ejercicios de marca que les proporcionarán lo que Pierre Bourdieu denomina una hexis corporal en consonancia con su categoria social. Pero no se trata únicamente de diferencias de contenidos y actividades sino que la dureza del encierro, el rigor de los castigos, el sometimiento a las órdenes, el distanciamiento de la autoridad, y la autopercepción que se les inculca son el fruto de la diferencia abismal que existe entre los preceptores domésticos, los colegios y "las escuelas de primeras letras" destinadas a los hijos de los pobres (VARELA; ALVAREZ-URÍA, 1991, p. 31).

Varela e Alvarez-Uría marcam a existência de três modos de educação na Idade Moderna, direcionadas de forma específica para a nobreza cortesã, a burguesia emergente/nobreza provinciana e as classes populares. Inspirados em trabalhos de Norbert Elias $(1989,1993)$, eles percebem que a nobreza da corte tinha uma educação refinada, realizada por preceptores, que visava o domínio da arte das armas e a educação nas letras e virtudes, destacando a trajetória social de Felipe II na Espanha do século XVI (VARELA, 1983, p. 28-56). Grosso modo, a burguesia e a nobreza provinciana geralmente frequentavam os colégios, que, na Pensínsula Ibérica, foram dominados pela Companhia de Jesus. Por fim, os sociólogos espanhóis consideram que as escolas de ler-escrever-contar e as instituições assistenciais dirigidas para as classes populares colocavam em marcha uma "disciplina-corpo" mais severa e rude, que previa ainda castigos corporais, destacando o trabalho dos escolápios ${ }^{4}$ na Espanha moderna. Nessa

4 Os escolápios foram fundados por São José de Calasanz em 1597, a partir de uma escola gratuita para meninos pobres na cidade de Roma, e oficializados pelo Papa Paulo V em 1622. Chegaram na Catalunha em 1648 e disseminaram-se na Espanha a partir da segunda metade do século XVII, dirigindo instituições assistenciais e educativas para as classes populares (RUIZ, 1998, p.126-127). 
direção, Varela e Alvarez-Uría chamam a atenção para o fato de a invenção da infância ocorrida a partir do século XVI, tematizada por Ariès (1981), é aquela das classes abastadas - nobreza cortesã e burguesia -, pois as classes populares estendem práticas medievais por vários séculos.

Entre os colégios jesuíticos e as escolas elementares de caridade dos lassalistas havia, portanto, diferenciação em relação ao disciplinamento corporal, que estava ligado à constituição estética dos diferentes estamentos sociais. A Ratio Studiorum previa um conjunto de estratégias disciplinares que deveriam ser colocadas em prática no cotidiano dos colégios da Companhia de Jesus. Essa "maquinaria escolar" (VARELA; ALVAREZ-URÍA, 1991, p. 13-54) implicava o controle do tempo, o esquadrinhamento do espaço, rígida hierarquia, emulação entre os alunos, incitamento ao trabalho permanente dos alunos, entre outros. Os castigos físicos também eram previstos no "código educativo dos jesuítas", mas como último recurso, quando "as boas palavras e exortações" não se mostravam eficazes. Segundo Ó (2003, p. 171), os jesuítas tinham uma escala progressiva de punições, de forma que os alunos maiores não sofriam castigos físicos e perceberam a eficácia de uma "disciplina auto-regulada". A rede de escolas idealizada e concretizada por La Salle também implementava dispositivos disciplinares parecidos àqueles previstos na Ratio Studiorum, mas eram menos refinados pelo fato de serem voltados às camadas populares urbanas.

Ademais, ao comentar a nova sensibilidade em relação à infância nas artes plásticas enunciada por Ariès (1981), Varela e Alvarez-Uría argumentam também que nas camadas abastadas da sociedade europeia houve desigualdade de gênero em relação à indumentária e às instituições educativas. Nessa direção, eles afirmam:

Será a partir del siglo XVII cuando el niño noble o burgués deje de vestirse como los adultos iniciándose así una moda particular para él, pues son los niños, y no las niñas, los primeros a los que afecta la especialización en el vestir, del mismo modo que serán los primeros en frecuentar los colegios (VARELA; ALVAREZ-URÍA, 1991, p. 24).

A educação proporcionada nos colégios modernos foi direcionada aos adolescentes do sexo masculino, que geralmente viabilizava o ingresso nos estudos superiores e as carreiras profissionais exitosas nas instituições estatais e nas empresas privadas (LOURO, 1997; VARELA, 1997).

Em relação ao ensino mútuo deve-se considerar que ele proporcionava a alfabetização em massa, especialmente da classe trabalhadora que se formava 
com a Revolução Industrial inglesa. Good (apud LÓPES; NARODOWSKI, 1999 , p. 68) afirma que "el sistema [monitorial] tenía por objeto la educación de los pobres y lo barato que resultaba era su atractivo principal. El costo por alumno era muy pequeño cuando las escuelas eran grandes ya que sólo requerían una persona asalariada: el director". Por esse motivo, o método mútuo foi apropriado pela maioria dos sistemas escolares estatais europeus e americanos na primeira metade do século XIX (LÓPES; NARODOWSKI, 1999). Logo após a emancipação política do Brasil, o método mútuo foi o prescrito oficialmente para as escolas de primeiras letras das províncias brasileiras por meio do Decreto Imperial de 15 de outubro de 1827 (BASTOS, 1999, p.114-115). Foucault flagrou as engrenagens disciplinares do método mútuo de forma arguta, que tinha estrutura piramidal, controle exaustivo do tempo e incitamento permanente ao trabalho. Contudo, ele não discute quais grupos sociais foram submetidos a essa escolarização em ritmo disciplinar.

Desta forma, constata-se que Foucault flagrou a disseminação do poder disciplinar nas instituições escolares, mas não diferenciou modos de educação que variaram a partir dos marcadores sociais religião, gênero e classe social. Em Vigiar e punir, ele não constatou o disciplinamento burguês que era colocado em marcha nos colégios jesuíticos que formavam uma rede mundial, sendo homogeneizados pela Ratio Studiorum. De outra parte, não procurou compreender as escolas elementares de caridade dos lassalistas e o método mútuo como instituições educativas das classes populares. Enfim, a análise do filósofo-historiador francês não primou por ler escolas de ler-escrever-contar e os colégios modernos numa clave sócio-histórica.

\section{Colocações finais}

Em Vigiar e punir, Foucault argumenta que na "época clássica", a disciplina passou a se disseminar pelo corpo social, formando a "sociedade disciplinar", que se consolidou no século XIX com o apogeu do panoptismo. Desta forma, nessa obra ele não dá muita visibilidade às rupturas sociais provocadas pelas reformas religiosas e guerras de religião e especialmente às implicações na invenção da tecnologia disciplinar. No entanto, em escritos posteriores, Foucault coloca o foco no deslocamento ocorrido no século XVI, como no brilhante ensaio "A governamentalidade" (FOUCAULT, 1979), resultado de um curso que ele ministrou no Collège de France. No início desse trabalho ele percebe que no século XVI o "governo" foi problematizado em relação a diferentes aspectos 
sociais, entre os quais o "problema do governo das crianças, problemática central da pedagogia". Esse recuo temporal permite perceber melhor o deslocamento que ocorreu no Ocidente na passagem do Medievo para a Idade Moderna, plasmado pela emergência da disciplina, particularmente nas instituições escolares vinculadas às igrejas protestantes e católico-tridentinas.

Enfim, Foucault construiu um novo olhar sobre o poder, que superou o seu caráter fixo e repressor, flagrando-o em pequenas operações tidas como ingênuas e cotidianas e em grandes estratégias de enquadramento da população. De forma inovadora e provocativa, ele não deu foco ao poder estatal, mas concedeu visibilidade à formação de instituições de corte disciplinar como as manufaturas, as instituições escolares, os quartéis, entre outras. No mundo disciplinar pós-medieval, as escolas de ler-escrever-contar e os colégios modernos de caráter confessional tiveram relevância ímpar na acumulação de seres humanos, muito particularmente os do gênero masculino. E a criação do "estado-educador" no espaço europeu, particularmente no final do século XIX não fez parte das reflexões históricas de Foucault.

Especificamente em Vigiar e punir, Foucault não confere um caráter sociológico ao poder disciplinar lido na perspectiva da longa duração, pois não lê a sua emergência e disseminação a partir dos conceitos de classe social e de gênero. O que lhe importa é constatar que a disciplina moderna é um objeto inventado no início da Idade Moderna, sendo reinventada e refinada na sociedade panóptica oitocentista. Esse limite sociológico não lhe permite constatar "dualismo escolar" da "disciplina-corpo" entre os colégios jesuíticos e as escolas elementares de caridade dos lassalistas, bem como o direcionamento do método mútuo para as classes populares na emergente industrialização inglesa.

\section{REFERÊNCIAS}

ARIÈS, P. História social da criança e da família. 2. ed. Rio de Janeiro: Guanabara, 1981. BASTOS, M. H. O ensino mútuo no Brasil (1808-1827). In: BASTOS, M. H.; FARIA FILHO, L. M. A escola elementar no século XIX: o método monitorial/mútuo. Passo Fundo: Ediupf, 1999. p. 95-118.

DEHEUVELS, P. Quelques Pages d'Histoire. In: LYCÉE LOUIS-LE-GRAND. Paris: Vies Editions, 2006. p. 7-15.

DUSSEL, I.; CARUSO, M. A invenção da sala de aula: uma genealogia das formas de ensinar. São Paulo: Moderna, 2003. 
ELIAS, N. El processo de la civilización: invetigacionais sociogenéticas y picogenéticas. España: Fondo de Cultura Económica, 1989.

La sociedad cortesana. Madrid: Fondo de Cultura Económica, 1993.

FIÉVET, M. Les enfants pauvres à l'école: la révolution scolaire de Jean-Baptiste de La Salle. Paris: Editions Imago, 2001.

FOUCAULT, M. A governamentalidade. In: Microfísica do poder. 7. ed. Rio de Janeiro: Edições Graal, 1979. p. 277-293.

FOUCAULT, M. Vigiar e punir: nascimento da prisão. 10. ed. Petrópolis, RJ: Vozes, 1993.

GOODSON, I. F. Currículo: teoria e história. Petrópolis, RJ: Vozes, 1995.

LELIÈVRE, C. Jules Ferry: La République éducatrice. Paris: Hachette Éducation, 1999. (Portraits d’Éducateurs).

LESAGE, P. A pedagogia nas escolas mútuas no século XIX. In: BASTOS, M. H.; FARIA FILHO, L. M. A escola elementar no século XIX: o método monitorial/mútuo. Passo Fundo: Ediupf, 1999. p. 9-24.

LÓPEZ, C.; NARODOWSKI, M. El mejor de los métodos posibles: la introducción del método lancasteriano en Iberoamérica en el temprano siglo XIX. In: BASTOS, M. H.; FARIA FILHO, L. M. A escola elementar no século XIX: o método monitorial/mútuo. Passo Fundo: Ediupf, 1999. p. 45-72.

LOURO, G. L. Gênero, sexualidade e educação: uma perspectiva pós-estruturalista. Petrópolis, RJ: Vozes, 1997.

MACHADO, R. Introdução Por uma genealogia do poder. In: FOUCAULT, M. Microfísica do poder. Rio de Janeiro: Edições Graal, 1979. p.VII-XXIII.

NARODOWSKI, M. Infancia y poder: la conformación de la pedagogia moderna. Buenos Aires: Aique Grupo Editor, 2008.

Ó, J. R. O governo de si mesmo: modernidade pedagógica e encenações disciplinares do aluno liceal (último quartel do século XIX-meados do século XX). Lisboa: EDUCA, 2003.

Ó, J. R. Notas sobre Foucault e a governamentalidade. In: FALÇÃO, Luiz Felipe; SOUZA, Pedro de. Michel Foucault: perspectivas. Rio de Janeiro: Achiamé, 2005. p. 15-39.

PETITAT, A. Produção da escola/produção da sociedade: análise sócio-histórica de alguns momentos decisivos da evolução escolar no Ocidente. Porto Alegre: Artes Médicas, 1994.

POPKEWITZ, T. S. História do currículo, Regulação Social e Poder. In: SILVA, T. T. (Org.). O sujeito da educação: estudos foucaultianos. Petrópolis, RJ: Vozes, 1994. p. 173-210.

RUIZ, E. M. (Ed.). Diccionario de historia moderna de España. Madrid: Ediciones ISTMO, 1998. (Fundamentos, 136). 
VARELA, J. Modos de educación en España de la Contrarreforma. Madrid: La Piqueta, 1983. (Geneaalogía del poder, 9).

. Nacimiento de la mujer burguesa. Madrid: La Piqueta, 1997. (Genealogía del poder, 30).

VARELA, J.; ALVAREZ-URÍA, F. Arqueología de la escuela. Madrid: La Piqueta, 1991.

Texto recebido em 05 de junho de 2013. Texto aprovado em 19 de dezembro de 2013. 